\title{
Assessment of knowledge, perceptions and acceptability of mandatory pre-medical tests for intending couples in churches in Abuja, Nigeria
}

\author{
A Uwah*1, A Adedeji1', O SalawuV, A Okunade1 ${ }^{1}$ P Adebayo ${ }^{2}$ and I Akpan ${ }^{3}$
}

\author{
Address: ${ }^{1}$ National AIDS and Sexually Transmitted Infections Control Program, Abuja, Nigeria, ${ }^{2}$ National Tuberculosis and Leprosy Control \\ Program, Abuja, Nigeria and ${ }^{3}$ Divine Assurance Zion Church, Abuja, Nigeria \\ Email: A Uwah* - uwah659@yahoo.com \\ * Corresponding author
}

from 2006 International Meeting of The Institute of Human Virology

Baltimore, USA. 17-2I November, 2006

Published: 21 December 2006

Retrovirology 2006, 3(Suppl I):P63 doi:10.1 I86/I742-4690-3-SI-P63

(C) 2006 Uwah et al; licensee BioMed Central Ltd.

\section{Background}

The mandatory STIs screening introduce in churches as preconditions for marriages play significant role in reducing the spread of STIs including HIV to unsuspected spouses including their children. This strategy was explored to assess the level of knowledge, perceptions and acceptability of this condition by intending couples in three faith-based organizations in Abuja, Nigeria.

\section{Methods}

Members of these institutions were identified trained and assigned as counselors as well as interviewers. Data collection tools were structured questionnaires and one-to-one interview. Socio-demographic data obtained were age, sex, level of education, occupation as well as awareness of STIs including HIV/AIDS.

\section{Results}

A total of 21 intending couples were interviewed. The survey period covered nine months. Levels of education were primary, secondary and post secondary consisting of varying forms of occupation while $5(2 \%)$ could not read or write. On awareness, $80 \%$ knew about STIs including HIV. $64 \%$ were aware of VCT and 59\% have had HIV test done before. Some of the couples however had the following perceptions with regard to HIV; 33\% believed they could not have HIV, $46 \%$ feared stigmatization and discrimination, $7 \%$ showed no interest for HIV testing while $14 \%$ believed that there is no confidentiality. Percentage of knowledge or known STIs were; gonorrhea 25\%, syphilis $9 \%$, candidasis $6 \%$, a chlamyda itrichomitis 7\%, HIV 50\% and trichomonas vaginalis $3 \%$. Among the previously tested, $14.2 \%$ and $8.2 \%$ represented pre-employment and volunteers respectively. Degree of awareness, perceptions and willingness to be tested were proportional to level of education.

\section{Conclusion}

This study showed varying responses and perceptions among couples about STIs including HIV testing. Awareness and counseling services could be better used among the sects. 